\title{
O design thinking como empatia, experimentação e colaboração na comunicação
}

DESIGN THINKING AS EMPATHY, EXPERIMENTATION AND COMMUNICATION CONTRIBUTION

\section{Tiago Costa Martins}

Bacharel em Comunicação Social, hab. Relações Públicas, pela Universidade Federal de Santa Maria (2002). Doutor em Desenvolvimento Regional pela Universidade de Santa Cruz do Sul (2014), com pesquisa no Exterior (bolsista PDSE/CAPES nº 18017126) na Universidade da Beira Interior - UBI, Laboratório de Comunicação - LabCom, Covilhã, Portugal (2013). Pós-doutor na UI\&D - Center for research in Communication, Information and Digital Culture CIC.DIGITAL Porto - Mestrado em Comunicação e Gestão das Indústrias Criativas, Universidade do Porto, Portugal (2018). Pesquisador Ministério da Cultura/CNPq Edital No 80/2013, Economia Criativa no Brasil (2013-2015). Pesquisador CNPq Edital Chamada Universal 01/2016, Comunicação Pública e Indicadores Culturais (2017-2020). Professor do Programa de Pós-graduação em Comunicação e Indústria Criativa - mestrado profissional, Unipampa. Professor Adjunto do Curso de Relações Públicas. Integrante do Grupo de Pesquisa "Processos e Práticas em Atividades Criativas e Culturais" (Unipampa/CNPq). Integrante do Observatório Missioneiro de Atividades Criativas e Culturais - OMiCult.

E-mail: tiagominuano@gmail.com

\section{Renata Fonseca Antunes}

Mestranda no Programa de Pós-graduação em comunicação e Indústria Criativa da Universidade Federal do Pampa - Campus São Borja. Formação em Comunicação Social: Publicidade e Propaganda - UNIPAMPA campus São Borja. Integrante do Grupo de Pesquisa Processos e Práticas nas Atividades Criativas e Culturais (GPAC)

E-mail: renataantunes182@hotmail.com

Recebido em 29/07/2018. Aprovado em 27/09/2018.

\section{Resumo}

Ressaltar a experiência dos consumidores pode ser reconhecida como uma estratégia para a comunicação. Por conta disso, considera-se relevante apostar em novos instrumentos, como no Design Thinking. O estudo propõe, ao indagar como formular processos de comunicação tendo como suporte a metodologia, apresentar o Design Thinking como apoio para esses processos, a partir de uma prática realizada na empresa Missões Júnior. As discussões do artigo relatam as etapas da metodologia aplicada à 
comunicação, descrevendo o caminho percorrido e as implicações nos processos comunicacionais. Como conclusão apontam-se algumas práticas de uso do Design Thinking, indicando uma alternativa às metodologias de planejamento da comunicação.

Palavras-chave: Design Thinking. Processo de comunicação. Metodologia.

\section{Abstract}

Highlighting the consumers experience can be considered a strategy to communication. Because of this, it is considered relevant to bet in new instruments as the Design thinking. The study aims, to inquire how to formulate communication processes having as a holder the method, to present the Design Thinking as the holder to these processes, starting from a practice made in the Missões Júnior enterprise. The article discussions relate the steps of the method applied to communication, describing the way coursed and the implications in the communicative processes. As a conclusion they are pointed some practices in the use of Design Thinking, indicating an alternative to communication planning methods.

Key-words: Design thinking. Communication process. Method.

\section{Introdução}

As mudanças econômicas e tecnológicas transformaram significativamente os comportamentos e as práticas na sociedade e no mercado. No âmbito da comunicação, por exemplo, o consumidor já não somente escuta o que a empresa e sua marca dizem, mas é parte do processo, atuando ativamente por diversos mecanismos de comunicação. Uma tendência, nesse sentido, é adaptar-se e ressaltar a experiência do consumidor como uma estratégia para os negócios. Dessa forma, a competição no mercado deixa de ser definida apenas em termos de características de produtos, sendo considerada também a qualidade da interação com os públicos.

Apostas em métodos tradicionais para entender e conquistar o consumidor nem sempre são consideradas suficientes. Adotar uma nova mentalidade que ressalte a empatia, experimentação e a colaboração, como propõe o Design Thinking, pode ser considerada um modo para entender com mais profundidade os desejos e necessidades das pessoas; como descobrem, avaliam, acessam, compram, usam, obtêm um produto/serviço (PINHEIRO; ALT, 2011).

O Design Thinking pode ser entendido como uma metodologia, porém não no sentido de oferecer um passo a passo, mas por trazer proposição de procedimentos (PINHEIRO; ALT, 2011). O processo é interativo, e o foco do projeto se encontra nas pessoas e suas 
etapas são combinadas de acordo com cada desafio. Além do mais, é possível empregá-lo em uma diversidade de contextos, entre os quais para formular processos de comunicação.

De acordo com Sant'Anna, Júnior e Garcia (2013, p. 2), de modo geral, o processo de comunicação consiste em um transmissor, uma mensagem e um receptor. Porém, o processo é complexo, nem sempre o receptor irá decodificar o que é transmitido, e "os sinais emitidos só têm significado se o receptor souber interpretá-los". Para que a comunicação se efetive é necessária a transmissão de ideias entre os indivíduos, de modo que haja entendimento entre as partes. É necessário haver uma troca de consciências. Comunicar, afirma Martino (2011), é o ato de compartilhar um mesmo objeto de consciência.

Quando aplicado à comunicação, o Design Thinking é capaz de possibilitar uma visão sobre o ambiente, com base no conhecimento dos atores que o cercam. Assim, facilita a identificação de como um produto/serviço está sendo visto e como sua disseminação, através da comunicação, pode ser realizada. Por envolver as pessoas na equipe do projeto, o Design Thinking favorece o entendimento entre as partes envolvidas, o compartilhamento de consciências, tornando possível a solução de uma necessidade de forma colaborativa.

É possível ampliar o entendimento em relação a isso ao se observar a aplicação da metodologia para solucionar uma necessidade comunicacional presente em determinado contexto. Para tanto, apresenta-se o caso da Missões Júnior ${ }^{1}$.

A empresa Missões Júnior, uma empresa júnior que presta serviços de desenvolvimento de software e suporte em termos de tecnologia da informação, é uma indústria criativa $^{2}$ produtora de serviço criativo, o software ${ }^{3}$. As produções implicam a formulação de softwares adequados às necessidades empresariais, transformando a forma de as organizações se comunicarem com a sociedade e com outras organizações.

No presente estudo indaga-se, com base no que está sendo exposto: como formular processos de comunicação tendo como suporte a metodologia do Design Thinking? Assim, o objetivo do estudo é apresentar o Design Thinking como apoio no planejamento de comunicação, a partir de uma prática realizada na empresa Missões Júnior.

O presente estudo divide-se, além desta introdução que procura situar o problema e objetivo, em mais duas seções, com suas subseções: "Design Thinking no processo de comunicação: resultados e discussões" e "Considerações finais: possibilidades do Design

1. Ligada ao curso superior de bacharelado em Sistemas de Informação, ofertado no Instituto Federal de Educação, Ciência e Tecnologia Farroupilha, de São Borja - RS.

2. Se refere a atividades que produzem produtos simbólicos dependentes da propriedade intelectual. Para maior entendimento ver a definição de Indústrias Criativas em Relatório de economia criativa, 2010.

3. O software, de acordo com a Conferência das Nações Unidas sobre Comércio e Desenvolvimento UNCTAD (2012), é um produto criativo, pois seu desenvolvimento e produção abarcam um esforço criativo e conceitual de solução de problemas e design. 
Thinking". Na primeira insere-se o conceito de Design Thinking. Posteriormente, aborda-se o Design Thinking no processo de comunicação para a Missões Júnior, e discute-se sobre o Duplo Diamante, que fornece uma compreensão sobre o processo que ocorre no Design Thinking. A partir disso, são apresentadas as etapas praticadas durante o processo. Por fim, na segunda parte constam as considerações da aplicação da metodologia na comunicação.

\section{Design Thinking no processo de comunicação: resultados e discussões}

Em um cenário mercadológico competitivo e contemplado por um público cada vez mais exigente, torna-se necessário renovar estratégias, adotar abordagens que valorizem o que é relevante, adaptável, prático, entre outros, para as pessoas (PINHEIRO; ALT, 2011). Nessa procura por novos caminhos é que se define a metodologia conhecida como Design Thinking. De acordo com Vianna,

[...] são equipes multidisciplinares que seguem um processo, entendendo os consumidores, funcionários e fornecedores no contexto onde se encontram, cocriando com os especialistas as soluções e prototipando para entender melhor as suas necessidades, gerando ao final novas soluções, geralmente inusitadas e inovadoras (VIANNA et al., 2012, p. 7).

Design Thinking significa o jeito de pensar do design, que centra o foco do projeto nas pessoas. Trata-se de uma abordagem, um novo modelo mental, uma nova forma de pensar e abordar problemas (PINHEIRO; ALT, 2011). A metodologia inclui, na equipe do projeto, pessoas de diferentes posições e formações - o cliente, o consumidor, o fornecedor, entre outros. Assim, é possível lançar olhares diversificados sobre determinada necessidade para, posteriormente, chegar a soluções.

A empatia, a colaboração e a experimentação são três elementos essenciais do Design Thinking, e "um profissional com estas três características está mais preparado e apto a solucionar problemas e liderar pessoas" (PINHEIRO; ALT, 2011, p. 12). Com isso, é possível aproximar-se dos consumidores, reduzir as chances de fracasso e abrir novas oportunidades para o negócio.

A empatia pode ser entendida como o hábito mental de "pensar nas pessoas como pessoas" (BROWN, 2010, p. 46). Trata-se da habilidade de compreender e viver os sen- 
timentos dos outros (PINHEIRO; ALT, 2011), visualizar os problemas e necessidades de determinado contexto por meio das experiências alheias.

A colaboração liga-se ao ato de realizar uma obra coletiva. As equipes multidisciplinares e o envolvimento de pessoas durante o desenvolvimento do projeto são de grande importância para gerar e selecionar ideias. Para tanto, são necessários espaços compartilhados, que "são verdadeiras ilhas de informação visual, que se encontram disponíveis durante todo o projeto, permitindo que a equipe navegue sem perder a linha de raciocínio" (PINHEIRO; ALT, 2011, p. 98). Em tais espaços são utilizadas paredes imantadas, painéis, quadro branco, ou qualquer forma necessária que possa servir como vitrine para guardar as informações do projeto. Esses espaços permitem que os clientes e consumidores reais ajudem a observar o contexto, criar soluções e tomar a melhor decisão.

A experimentação refere-se ao ato de analisar os possíveis resultados para colher feedbacks. Experimentar permite evitar e consertar grandes erros. De acordo com Pinheiro e Alt (2011), é menos frustrante errar cedo para aprender logo. Às vezes é necessário realizar diversas tentativas para, enfim, acertar o alvo, até porque cada tentativa errada coloca a equipe um passo adiante. É difícil um projeto iniciar com todas as barreiras e dificuldades traçadas. Por conta disso, torna-se relevante experimentar, refletir sobre formas rentáveis para concretizar um projeto.

É considerado, ao contemplar os três elementos citados, o que é desejável para as pessoas, financeiramente possível para o negócio e possível de ser produzido e implementado. O modelo mental pode ser aplicado em uma diversidade de contextos. Por exemplo, no processo de criação de uma plataforma de serviços web para fãs de Beatles (VELASQUES; MÜLLING, 2013); em um projeto de software para Mobilidade Urbana (ALVES; et al., 2014); para identificar problemas em um sistema de ensino (SILVA; et al., 2016), entre outros.

\section{O Design Thinking no processo de comunicação para a Missões Júnior}

O processo de comunicação para a Missões Júnior desenvolveu-se através do projeto de Pesquisa, Desenvolvimento e Inovação (PD\&I), apresentado ao Programa de Pós-Graduação em Comunicação e Indústria Criativa (PPGCIC), da Universidade Federal do Pampa (UNIPAMPA), campus São Borja, RS. A ação comunicacional, conforme a linha de pesquisa seguida no programa, é compreendida como um processo que auxilia uma indústria criativa. A comunicação é pensada para uma indústria criativa. 
A Missões Júnior, por ser uma produtora de softwares, é compreendida enquanto uma indústria criativa. Conforme a Unctad, as indústrias são

[...] os ciclos de criação, produção e distribuição de produtos e serviços que utilizam criatividade e capital intelectual como insumos primários; constituem um conjunto de atividades baseadas em conhecimento, focadas, entre outros, nas artes, que potencialmente gerem receitas de vendas e direitos de propriedade intelectual; constituem produtos tangíveis e serviços intelectuais ou artísticos intangíveis com conteúdo criativo, valor econômico e objetivos de mercado; posicionam-se no cruzamento entre os setores artísticos, de serviços e industriais; e constituem um novo setor dinâmico no comércio mundial (UNCTAD, 2012, p. 8).

A Unctad (2012), portanto, classifica as indústrias criativas em: patrimônio, artes, mídia e criações funcionais. Dentro do grupo das criações funcionais é possível observar o grupo das novas mídias, que envolve o conteúdo digital criativo, videogames e o software. O software é tido como "um produto criativo em si, que se expressa através de formas digitais de conteúdo criativo" (UNCTAD, 2012, p. 158).

\section{O Duplo Diamante do Design Thinking no processo de comunicação}

Instituições e consultorias de inovação fornecem o entendimento sobre o processo que ocorre no Design Thinking. O Design Council, órgão público do Reino Unido, através de uma pesquisa realizada com onze empresas para identificar como o pensamento do Design era tangibilizado, identificou que o processo de condução de projetos possui cerca de dois estados fundamentais: "expandir o entendimento sobre o desafio enfrentado e o de refinar o conhecimento adquirido para encontrar novas ações e significados" (PINHEIRO; ALT, 2011, p. 43). Nesse processo, primeiro são geradas opções (expandir), para depois traçar o caminho (refinar).

O processo de expandir e refinar observado pelo Design Council recebeu o nome de Diamante Duplo. O Diamante Duplo não se refere a um modelo linear, "é livre para seguir uma natureza interativa" (PINHEIRO; ALT, 2011, p. 44). É composto por quatro etapas: descobrir (diverge), definir (converge), desenvolver (diverge) e entregar (converge). 


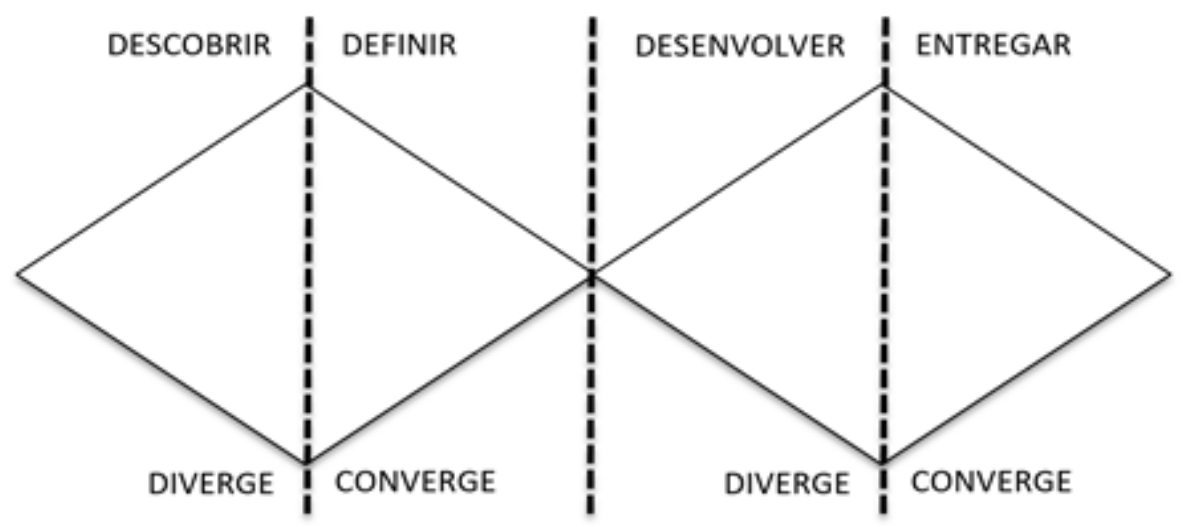

Figura 1 - Duplo Diamante

Fonte: Adaptado de Pinheiro e Alt (2011).

Conforme exposto na Figura 1, durante as etapas "descobrir e desenvolver" o conhecimento é expandido (diverge). Nas etapas "definir e entregar" são feitas escolhas, as informações obtidas passam por um processo de refinamento (converge).

Durante o processo de comunicação para a Missões Júnior foi possível constatar o que está sendo exposto na prática. O duplo diamante do processo realizado na empresa passou pelas seguintes etapas: (1) pesquisa exploratória, pesquisa desk e entrevista (descobrir); (2) mapa conceitual e definição do perfil do público (definir); (3) mapa conceitual, mapa de expectativas e diagrama de afinidades (desenvolver); (4) protótipo e guia de referências (entregar), conforme descrito a seguir.

\section{Descobrir: primeira etapa}

Essa etapa serviu para construir a base conceitual, identificar problemas e gerar insights. Desde o início a empatia foi exercida, as questões foram consideradas a partir do olhar do outro. A etapa foi alcançada através da realização de pesquisa exploratória, pesquisa desk e entrevistas.

\section{Pesquisa Exploratória}

A pesquisa exploratória auxiliou no entendimento do contexto que seria trabalhado, fornecendo insumos para a definição dos perfis dos públicos e informações sobre o produto. Além disso, ajudou na elaboração de questões que precisavam ser mais bem investigadas na Pesquisa Desk. Como apoio para a geração do conteúdo foi consultado o Projeto Pedagógico do Curso. 


\section{Pesquisa desk}

Posteriormente houve a realização da pesquisa desk, com base em referências da internet. Houve uma busca de informações sobre o objeto do projeto nas fontes websites, $b \log s$, artigos, entre outros. A pesquisa auxiliou na obtenção de maior entendimento sobre os meios de comunicação utilizados. Foi possível identificar que o curso conta com uma página no Sistema Integrado de Gestão de Atividades Acadêmicas (SIGAA), que apresenta informações gerais acadêmicas de todos os cursos da instituição para o público externo e é utilizado como uma forma de interação entre docentes e discentes; um blog, que se encontra fora de funcionamento; o site institucional do IFFar que apresenta eventos relacionados; e o projeto pedagógico disponibilizado na internet. Em relação a Missões Júnior, a empresa conta com um site e atendimento interpessoal, por telefone e e-mail.

\section{Entrevistas}

As entrevistas foram realizadas com base nas informações levantadas nas pesquisas anteriores. Elas auxiliaram na tentativa de articular, com as pessoas que fazem parte do contexto abordado, necessidades que poderiam não saber que as tinham. Os entrevistados possuíam perfil de aluno, professor e cliente da empresa júnior, públicos que se relacionam com o curso e com a empresa.

As entrevistas realizadas permitiram gerar uma base para a definição do perfil do público, entender os meios que as pessoas envolvidas com o contexto mais utilizam, as principais características dos produtos, entre outros. As entrevistas foram relevantes no sentido de ampliar o entendimento sobre o contexto abordado e ajudar os envolvidos a articularem necessidades ligadas à comunicação.

\section{Definir: segunda etapa}

Na segunda etapa ocorreu o encerramento da primeira fase para que fosse possível filtrar resultados. Nesse momento foi preciso pensar no melhor direcionamento, reunir as informações e analisá-las para convertê-las em uma única resposta. Para isso houve a formulação de um mapa conceitual e o estudo do perfil do público. 


\section{Mapa Conceitual}

Foi produzido um mapa com palavras-chave para desencadear uma reflexão em conjunto, focada na empresa júnior. Com base em elementos que se ligam à empresa, foram trazidas as palavras-chave: Missões Júnior; produtos/serviços; Instituto Federal Farroupilha; público; e comunicação. O mapa foi utilizado na terceira etapa do projeto para gerar uma reflexão em conjunto e instigar a discussão sobre propostas de comunicação.

\section{Perfil do público}

As informações obtidas nas pesquisas anteriores auxiliaram a cruzar e analisar padrões que caracterizassem o perfil do público. Como resultado, foi possível constatar que o público possuía perfil tecnológico, se enquadrava enquanto colaborador de uma organização, podendo se tornar cliente ou parceria da empresa; aluno e possível aluno, podendo tornar-se sócio ou funcionário; e professor, podendo tornar-se gestor da empresa.

\section{Desenvolver: terceira etapa}

$\mathrm{Na}$ terceira etapa do projeto aconteceu o levantamento do maior número de possibilidades possível que levassem a uma solução. Para isso, foi considerada a importância da colaboração. A equipe era multidisciplinar e o envolvimento das pessoas durante o desenvolvimento do projeto foi importante para gerar e selecionar ideias.

A etapa foi alcançada em dois momentos: (1) no primeiro houve um levantamento de propostas para a comunicação, mediante a utilização do mapa conceitual, descrito anteriormente, e do mapa de expectativas; (2) no segundo momento as ideias foram organizadas, visando o melhor direcionamento. Para tanto, foi utilizada a ferramenta diagrama de afinidades.

A equipe, composta por alunos, professores, integrantes e cliente da empresa, auxiliou a observar, sob diferentes perspectivas, a comunicação da empresa. No espaço de realização da atividade foram disponibilizados lápis, canetas, folhas A4, cartolinas, post $i t$. No ambiente foi organizado um painel que permitiu as colagens das produções em andamento, facilitando a revisão de anotações e inspiração. Além disso, para as atividades foram estipulados intervalos de tempo finitos, e criados prazos de entrega para manter a equipe concentrada e controlar o tempo da atividade. 


\section{Mapa Conceitual}

O Mapa Conceitual foi utilizado para gerar uma reflexão em conjunto sobre assuntos relacionados à empresa. As palavras-chave que serviram para desencadear essa reflexão foram inseridas em um painel. No decorrer da conversa os participantes foram realizando anotações em post it e completando o painel.

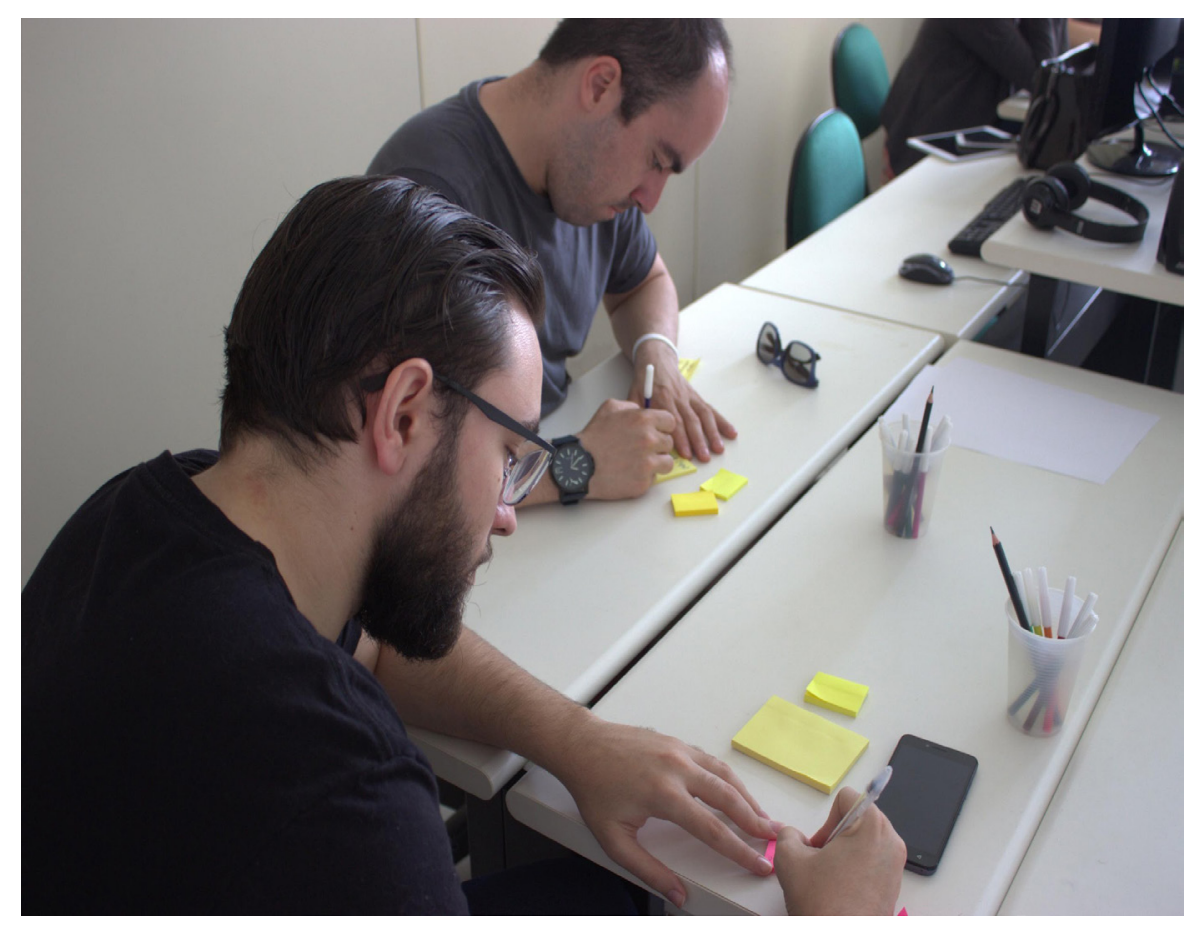

Figura 2 - Atividade Mapa Conceitual.

Fonte: Antunes (2017).

Como forma de desencadear a reflexão foram realizados, entre outros, os seguintes questionamentos: Como os produtos e os serviços que a empresa oferece auxiliam as pessoas? Como a empresa ajuda no ensino? Como a instituição de ensino pode dar assistência a Missões Júnior? Quem procura a empresa? Como a empresa conversa com seus clientes? Qual o caminho que uma pessoa faz para chegar até a empresa? Como as pessoas ficam sabendo dessas produções?

O exercício, através de uma visualização gráfica, permitiu extrair novos significados dos elementos-chave expostos. Com essa discussão em conjunto foi possível realizar comparações do ponto de vista do público interno e externo sobre o que é, e o que poderia ser feito em termos de comunicação. A atividade serviu de base para a geração de ideias. 


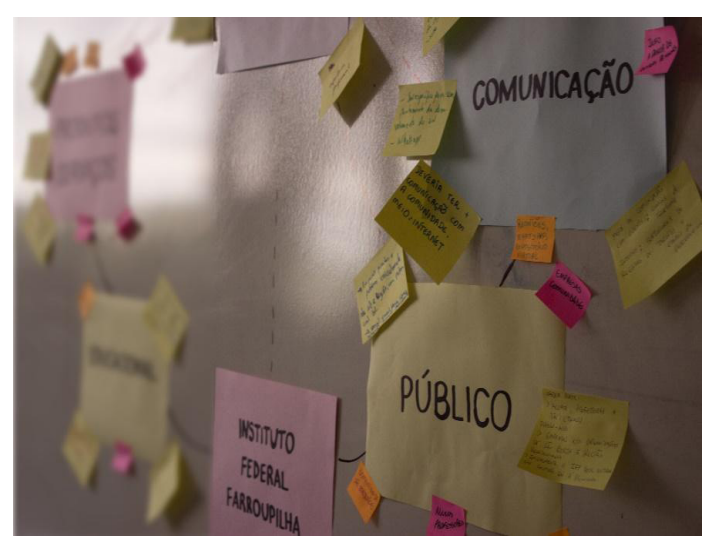

Figura 3 - Mapa Conceitual

Fonte: Antunes (2017).

A atividade, que auxiliou na reflexão sobre como a empresa estava e como desejava ser vista, quais formas de comunicação utiliza e como poderia ampliá-las, serviu de base para a geração de ideias na atividade posterior.

\section{Mapa de expectativas}

O mapa de expectativas foi utilizado para investigar e mapear as expectativas dos usuários, para entender como eles desejavam interagir com a empresa. Para dar início a essa reflexão foram discutidos alguns exemplos de propostas de comunicação. Posteriormente, a equipe foi separada em dois grupos. Foi solicitado aos grupos que discutissem em conjunto, considerando a reflexão realizada na atividade anterior, propostas de comunicação. E para que ilustrassem suas ideias foram disponibilizados lápis, canetas, cartolinas, post it, folhas A4, entre outros.

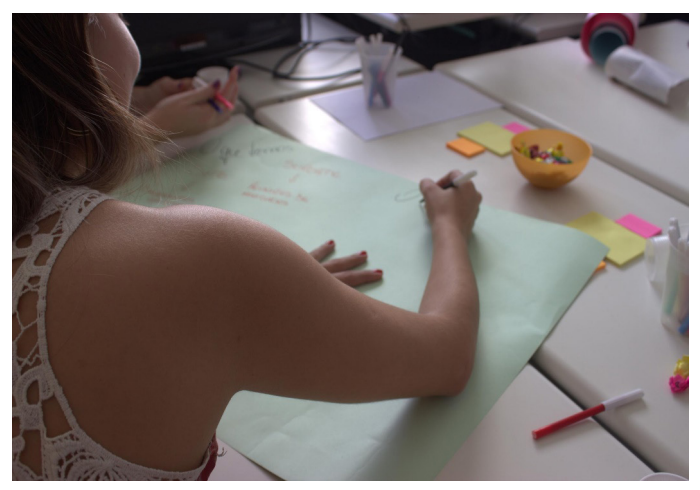

Figura 4 - Mapa de expectativas

Fonte: Antunes (2017). 
As propostas foram discutidas considerando-se critérios como da viabilidade de implementação. Durante o desenvolvimento da atividade, por meio de um relato, foi constatado que, no cenário atual, a empresa possui uma estrutura limitada e por conta disso uma quantidade de funcionários limitada, não podendo aumentar a demanda de serviços drasticamente. Por questões de estrutura e financeiras, ações de comunicação em massa, como o anúncio na rádio, deixaram de ser consideradas prioridades no momento. Porém, ações direcionadas a plataformas e redes sociais continuaram sendo consideradas, por não envolverem custos adicionais e serem locais onde parte do público de interesse da empresa navega.

\section{Diagrama de Afinidades}

A ferramenta foi utilizada para que fosse possível organizar e analisar as ideias geradas anteriormente. As propostas geradas foram organizadas com base em afinidade. Como resultado, foram agrupadas em eventos e conteúdo digital. Em relação aos eventos, a equipe considerou relevante a participação da empresa em reuniões empresariais e a formulação de uma Mostra da empresa. Além disso, houve a reflexão sobre a importância em dar início a um projeto que possibilitasse a identificação de pontos que poderiam ser melhorados na empresa.

O primeiro refere-se ao "Troca de experiência no café da manhã", realizado pela Associação Comercial e Industrial de São Borja (ACISB) em parceria com outras associações. O evento reúne organizações de diferentes setores e procura qualificar e engajar as empresas na distribuição de seus produtos e serviços. Dessa forma, foi visto como uma forma de ampliar a rede de contatos e divulgar a empresa no cenário organizacional.

$\mathrm{O}$ segundo, referente à Mostra da Missões Júnior, foi visto como relevante por possibilitar o esclarecimento de dúvidas sobre a empresa e suas produções. Trata-se de um evento destinado a promover o intercâmbio de conhecimentos, relacionados à empresa, entre os estudantes. Um espaço para palestras e divulgação de trabalhos desenvolvidos pela empresa, compartilhamento de ideias e sugestões. A mostra foi pensada para ter como palestrantes os professores e alunos que integram a empresa; como público geral, os alunos de todos os semestres do bacharelado; e como público específico, os ligados aos primeiros semestres, por necessitarem de uma ampliação das fronteiras do conhecimento.

$\mathrm{O}$ terceiro foi considerado relevante pela equipe por possibilitar o diagnóstico de pontos que necessitam de maior atenção na empresa. O projeto foi pensado com a 
intenção de destinar um turno do trabalho, uma vez na semana, para que os integrantes da empresa pudessem refletir sobre iniciativas ou continuidade de projetos, como os relacionados à área de comunicação. A cada final de semestre na empresa, ou a cada encerramento de proposta, os projetos seriam apresentados e avaliados. Como resultado dessa ação a empresa conseguiria observar, pelos diferentes pontos de vista, o que poderia ser feito para atender as carências percebidas.

Em relação ao conteúdo digital, segundo grupo, foram refletidos conteúdos em formato de imagem e vídeo para serem veiculados no meio digital — no site, plataformas e redes sociais. Uma das propostas se refere à transmissão de informação sobre a empresa de forma infográfica, em cartazes, pois o infográfico é considerado um modo atrativo e diferenciado de informar. Sobre a comunicação em forma de vídeo, houve a proposta da formulação de audiovisuais. Considerando-se que em um minuto é possível transmitir uma variedade de ideias e palavras que uma pessoa não teria tempo e disposição para ler, caso fossem escritas, a reflexão aconteceu em torno da formulação de um vídeo institucional da empresa, no intuito de tornar conhecidas suas produções e valorizar sua imagem no cenário organizacional.

Além disso, considerando-se o site - produto dessa indústria criativa - uma das formas de expor o trabalho da empresa, foram elaboradas estratégias para direcionar as pessoas para ele. Assim, as propostas de plataformas e redes sociais foram consideradas relevantes, como forma de direcionar o público para o site.

\section{Entregar: quarta etapa}

Nessa etapa, com base nos resultados obtidos anteriormente, as propostas foram testadas e concretizadas em produtos de comunicação. Para isso, foi realizado o protótipo que permitiu experimentar. A experimentação auxiliou no ato de analisar os possíveis resultados e a colher feedbacks, e permitiu evitar e consertar grandes erros.

\section{Protótipo}

Os protótipos das propostas foram discutidos, e posteriormente ocorreu o desenvolvimento das ações. Foram produzidos o vídeo institucional, os cartazes, o canal no Youtube e as redes sociais. A empresa realizou um primeiro contato com a ACISB, para sua inclusão no Troca de Experiências no Café da Manhã. Para o desenvolvimento (pla- 
nejamento e execução) da Mostra, conseguiu uma parceria com o Ensino Médio integrado em eventos, presente na mesma instituição de ensino. Além destes, passou planejar a adequação do projeto Intraempreendedorismo dentro do seu expediente.

\section{Guia de Referências}

Por fim, foi produzido um documento para preservar a estrutura do projeto e possibilitar o entendimento de como ocorreu seu funcionamento. O guia sobre o projeto foi formulado para permitir que outras pessoas, não familiarizadas com a ideia, ou que não participaram do processo desde o início, pudessem obter informações precisas para prosseguir, no sentido de gerar contribuições adicionais sem prejudicar o caminho percorrido.

\section{Considerações finais: possibilidades do Design Thinking}

Percebe-se, através do caso da Missões Júnior, como é possível apropriar-se do Design Thinking em um planejamento de comunicação. A metodologia permite identificar como a comunicação está sendo vista pelo público de interesse de uma organização, além de como pode ser reconfigurada.

O Design Thinking torna possível compreender as barreiras responsáveis por impedir que um produto/serviço seja bem aceito pelas pessoas (PINHEIRO; ALT, 2011, p. 26). Permite a identificação de necessidades que não estão sendo atendidas. Os três pilares da metodologia - empatia, colaboração e experimentação - promovem a empatia entre as pessoas e possibilitam que sejam produzidas respostas apropriadas à situação dos indivíduos que interagem com o contexto. Também permite que as soluções sejam construídas com base na união, mostrando que a participação ativa dos agentes é capaz de gerar soluções para processos ou produtos comunicacionais. Além disso, possibilita reduzir riscos através da experimentação.

A metodologia, ao envolver os consumidores, clientes, fornecedores, entre outros, na equipe do projeto, favorece o entendimento entre as partes envolvidas, torna possível a solução de uma necessidade de modo colaborativo (PINHEIRO; ALT, 2011). As ferramentas advindas do Design Thinking demonstram como é possível elaborar processos colaborativos. Assim, ao ser utilizado como apoio para formular ou reformular a comunicação, o Design Thinking permite que o olhar dos especialistas seja considerado, e suas necessidades e desejos sejam destacados. A solução é pensada de modo 
a ser boa para as empresas e para as pessoas. Abre-se espaço para o compartilhamento de consciências.

A abordagem permite observar, por diferentes pontos de vista, como a comunicação está sendo estabelecida, o que precisa de ser modificado, produzido, onde é necessário investir, entre outros. A metodologia auxilia no processo de tomada de decisões, com base no que é desejável para as pessoas, financeiramente adequado para o negócio e possível de ser produzido e implementado (PINHEIRO; ALT, 2011). São utilizados diversos processos mentais para chegar a uma solução, e, nesse curso, a criatividade é estimulada, trabalhada de modo que os colaboradores encontrem soluções eficazes para os problemas. O projeto é, desse modo, desenvolvido com base no olhar das pessoas, que auxiliam o processo de tomada de decisões. Situação que, diante de novos processos e produtos tecnológicos, parece ser necessária para o contexto em que se estabelece a comunicação na atualidade.

\section{Referências}

ALVES, Antonia T.; et al. Relato da Aplicação da Metodologia Design Thinking no Projeto de um Software para Mobilidade Urbana. Disponível em: <http://www.lbd.dcc.ufmg.br/colecoes/ sbsi/2014/0028.pdf >. Acesso em: 05 jun. 2018.

BROWN, Tim. Design Thinking: uma metodologia poderosa para decretar o fim das velhas ideias. $11^{\circ}$ reimpressão. Rio de Janeiro: Elsevier, 2010.

MARTINO, Luiz C. De qual comunicação estamos falando? In: HOHLFELDT, Antônio; MARTINO, Luiz C.; FRANÇA, Vera Veiga. Teorias da comunicação: Conceitos, escolas e tendências. Petrópolis, RJ: Vozes, 2011. p. 11-25.

PINHEIRO, Tennyson; ALT, Luis. Design Thinking Brasil: empatia, colaboração e experimentação para pessoas, negócios e sociedade. Rio de janeiro: Elsevier, 2011.

SANT'ANNA, Arnaldo; JÚNIOR, Ismael Rocha; GARCIA, Luiz Fernando Dabul. Propaganda: teoria, técnica e prática. São Paulo: Cengage Learning, 2013.

SILVA, Alexsandra M.; et al. Aplicação do Design Thinking em um Problema Educacional: Um Relato de Experiência. Disponível em: <http://br-ie.org/pub/index.php/wie/article/ view/6634/4545>. Acesso em: 12 jun. 2018. 
UNCTAD - UNITED NATIONS CONFERENCE ON TRADE AND DEVELOPMENT. Relatório das atividades criativas: economia criativa - uma opção de desenvolvimento viável. UNCTAD, 2010. Disponível em: <http://unctad.org/pt/docs/ditctab20103_pt.pdf>. Acesso em: 23 nov. 2017.

VIANNA, Maurício et al. Design Thinking: inovação em negócios - Rio de Janeiro: MJV Press, 2012.

VELASQUES, Taline Sabany. MÜLLING, Tobias Tessman. All you need is love: O Design Thinking como suporte ao desenvolvimento de uma plataforma de serviços. Revista de Iniciação Científica, Tecnológica e Artística - Edição Temática: Comunicação, Arquitetura e Design, São Paulo, v. 3, n.1, p. 1-20, jan. 2014. 